\title{
Sulfated Alkyl Glucopyranans with Potent Antiviral Activity Synthesized by Ring-Opening Copolymerization of Anhydroglucose and Alkyl Anhydroglucose Monomers
}

\author{
Shiming Bai, ${ }^{1}$ Davaanyam Budragchaa, ${ }^{1}$ Shuqin Han, ${ }^{1}$ Taisei Kanamoto, ${ }^{2}$ \\ Hideki Nakashima, ${ }^{2}$ and Takashi Yoshida ${ }^{1,3}$ \\ ${ }^{1}$ Department of Bio and Environmental Chemistry, Kitami Institute of Technology, 165 Koen-cho, Kitami, Hokkaido 090-8507, Japan \\ ${ }^{2}$ St. Marianna University School of Medicine, Miyamae-ku, Kawasaki 216-8511, Japan \\ ${ }^{3}$ Research Center for Environmentally Friendly Materials Engineering, Muroran Institute of Technology, 27-1 Mizumoto-cho, \\ Muroran, Hokkaido 050-8585, Japan
}

Correspondence should be addressed to Takashi Yoshida; yoshida@chem.kitami-it.ac.jp

Received 20 January 2015; Accepted 26 May 2015

Academic Editor: Huining Xiao

Copyright (c) 2015 Shiming Bai et al. This is an open access article distributed under the Creative Commons Attribution License, which permits unrestricted use, distribution, and reproduction in any medium, provided the original work is properly cited.

\begin{abstract}
Sulfated glucopyranans having long alkyl groups were prepared by the ring-opening copolymerization of benzylated 1,6anhydroglucopyranose with 3-O-octadecyl 1,6-anhydro- $\beta$-D-glucopyranose monomers, and subsequent deprotection and sulfation. Water-soluble sulfated glucopyranans with 2.8 and $4.7 \mathrm{~mol} \%$ of 3-O-octadecyl group and lower molecular weights of $\bar{M}_{n}=$ $2.5 \times 10^{3}-5.1 \times 10^{3}$ have potent anti-HIV activity at $0.05-1.25 \mu \mathrm{g} / \mathrm{mL}$, even though sulfated polysaccharides with molecular weights below $\bar{M}_{n}=6 \times 10^{3}$ had low anti-HIV activity. The interaction with poly-L-lysine as a model compound of proteins was analyzed by SPR, DSL, and zeta potential, indicating that the sulfated 3-O-octadecyl glucopyranans had high association and low dissociation rate constants, and the particle size increased after addition of poly-L-lysine. The anti-HIV activity was induced by electrostatic interaction between sulfate groups and amino groups of poly-L-lysine and by the synergistic effect of the hydrophobic long alkyl chain and hydrophilic sulfated group.
\end{abstract}

\section{Introduction}

We have continuously investigated the ring-opening polymerization of anhydrosugar derivatives, which is a superior method to prepare stereoregular polysaccharides with high molecular weights and defined structures $[1,2]$ and elucidation of the relationship between the structure and biological activity of polysaccharides $[3,4]$. Since the first report on the ring-opening polymerization of 2,3,4-tri-Obenzyl 1,6-anhydro- $\beta$-D-glucopyranose monomer (LGTBE) into stereoregular $(1 \rightarrow 6)$ - $\alpha$-D-glucopyranan by Ruckel and Schuerch in 1966 [5], synthesis and polymerization of several anhydrosugar derivatives were reported. We have also synthesized many anhydropentose and hexose derivatives that were polymerized to give stereoregular polysaccharides after deprotection of the hydroxyl protective groups [6]. It is important to obtain polysaccharides with desired molecular weights and defined structures for the investigation of the structure-biological activity relationship, because there are many naturally occurring polysaccharides that have specific biological activities; however, in general, they have very complex structures and it is difficult to know the relationship.

Curdlan sulfate, which was synthesized by sulfation of naturally occurring curdlan with a linear $(1 \rightarrow 3)-\beta$-Dglucopyranoside structure [7], was found to have potent antiHIV activity in the infection of MT-4 cells with HIV at completely inhibitory concentrations as low as $3.3 \mu \mathrm{g} / \mathrm{mL}$ and the activity depended on the molecular weights and degree of sulfation [6]. We introduced a long alkyl chain into curdlan sulfates with high anti-HIV activity by the ionic interaction of sulfate groups and quaternary ammonium salt of the long alkyl chain. A membrane filter was coated with the alkyl curdlan sulfates due to the hydrophobic interaction of the long alkyl chains with the surface of the membrane 
TABLE 1: Ring-opening copolymerization of 2,3,4-tri-O-benzyl (LGTBE) with 2,4-di-O-benzyl-3-O-octadecyl 1,6-anhydro- $\alpha$-D-glucopyranose LGDBE3-18 ${ }^{\mathrm{a}}$.

\begin{tabular}{|c|c|c|c|c|c|c|c|c|c|}
\hline \multirow{2}{*}{ Number } & \multicolumn{2}{|c|}{ LGTBE } & \multicolumn{2}{|c|}{ LGDBE3-18 } & \multicolumn{5}{|c|}{ Polymer } \\
\hline & $\mathrm{g}$ & $\mathrm{mol} \%$ & g & $\mathrm{mol} \%$ & $\begin{array}{c}\text { Time } \\
\mathrm{h}\end{array}$ & $\begin{array}{c}\text { Yield } \\
\%\end{array}$ & $\begin{array}{l}\bar{M}_{n}^{\mathrm{b}} \\
\times 10^{3}\end{array}$ & $\begin{array}{c}\text { LGDBE3-18 } \\
\text { units in } \\
\text { polymer }^{\mathrm{c}}\end{array}$ & $\begin{array}{c}{[\alpha]_{\mathrm{D}}^{25}} \\
\operatorname{deg}\end{array}$ \\
\hline 1 & 0.5 & 100 & 0 & 0 & 0.5 & 82.5 & 59.1 & 0 & +114.1 \\
\hline 2 & 0.475 & 96.3 & 0.025 & 3.7 & 4 & 91.9 & 83.5 & 1.3 & +111.2 \\
\hline 3 & 0.45 & 95 & 0.05 & 5 & 4 & 90.6 & 117.6 & 3.2 & +111.6 \\
\hline 4 & 0.425 & 90 & 0.075 & 10 & 4 & 89.7 & 65.7 & 4.7 & +107.8 \\
\hline 5 & 0.325 & 70 & 0.175 & 30 & 4 & 91.9 & 112.5 & 22.2 & +101.2 \\
\hline 6 & 0.08 & 50 & 0.12 & 50 & 4 & 92.7 & 136.5 & 46.9 & +92.5 \\
\hline 7 & 0.05 & 30 & 0.15 & 70 & 4 & 94.3 & 128.2 & 72.9 & +91.4 \\
\hline 8 & 0 & 0 & 0.2 & 100 & 4 & 91.8 & 163.1 & 100 & +86.9 \\
\hline
\end{tabular}

${ }^{\mathrm{a}}$ Total monomer weight: 0.2 and $0.5 \mathrm{~g}$, solvent: $\mathrm{CH}_{5} \mathrm{Cl}_{5} ; 0.4 \mathrm{~mL}$, catalyst: $\mathrm{PF}_{5} ; 5 \mathrm{~mol} \%$, temperature: $-60^{\circ} \mathrm{C}$.

${ }^{\mathrm{b}}$ Determined by GPC.

${ }^{\mathrm{c}}$ Calculated from ${ }^{1} \mathrm{H}$ NMR spectrum (mol\%).

filter to develop curdlan sulfate-coated membrane filters. We found that the membrane filter removed influenza A viruses at dilutions below 1:32 [8]. In addition, curdlan sulfate was shown to effectively inhibit Dengue virus replication in different cells [9]. The minimum 50\% effective concentration $\left(\mathrm{EC}_{50}\right)$ was as low as $0.1 \mu \mathrm{g} / \mathrm{mL}$ in LLCMK2 cells. The cytotoxicity of curdlan sulfate was quite low because no inhibitory effects on cell growth were observed in concentrations as high as $5000 \mu \mathrm{g} / \mathrm{mL}$. We assumed that the biological activity of sulfated polysaccharides was due to the electrostatic interaction between negatively charged sulfate groups and positively charged envelope proteins of the viruses. The interaction between sulfated polysaccharides and poly-L-lysine as a model compound of proteins was quantitatively investigated by surface plasmon resonance (SPR) measurements, suggesting that sulfated polysaccharides had fast association and slow dissociation rates on the immobilized poly-L-lysine [10]. These results indicate a high stability of the interaction.

Sulfated ribofuranan and ribopyranan with five- and sixmembered ring structures, respectively, obtained by the ringopening polymerization of benzylated and benzylidenated anhydroribose monomers [3], were found to have high antiHIV activities [6]. Although sulfated ribofuranan showed higher blood anticoagulant activity at 56 units/mg, sulfated ribopyranan had the lower activity of 29 units/mg, probably because the furanosidic structure had a flexible main chain so that the interaction with proteins became stronger. Furthermore, higher molecular weights and degrees of sulfation of sulfated polysaccharides showed higher biological activities. On the other hand, sulfated polysaccharides with low molecular weights had low anti-HIV activity. However, after introduction of an octadecyl group into sulfated ribofuranans with low molecular weights, the anti-HIV activity increased to a level almost comparable to that of curdlan sulfate with a higher molecular weight and high anti-HIV activity.

In this paper, we report the synthesis of sulfated alkyl polysaccharides by the ring-opening copolymerization of
LGTBE with 2,4-di-O-benzyl 3-O-octadecyl-1,6-anhydro- $\beta$ D-glucopyranose (LGDBE3-18) and subsequent debenzylation to recover hydroxyl groups without elimination of the 3-O-octadecyl group. After sulfation, we found that sulfated 3-O-octadecyl glucopyranans with lower molecular weights had potent anti-HIV activity. The structure of polysaccharides obtained was determined by high resolution NMR and the interaction with poly-L-lysine as a model compound of proteins was quantitatively measured by SPR, DSL, and zeta potential measurements. The final purpose of the work was to develop bioactive materials such as membrane filters for removal of HIV, Dengue, and influenza viruses.

\section{Materials and Methods}

2.1. Materials. 2,3,4-Tri-O-benzyl (LGTBE) and 2,4-di$O$-benzyl-3-O-octadecyl 1,6-anhydro- $\beta$-D-glucopyranose (LGDBE3-18) monomers were prepared according to the modified method of previous papers, respectively $[5,11]$. Piperidine- $N$-sulfonic acid was synthesized by the reported method [12]. Other reagents were purchased from commercially available products and used without further purification.

2.2. Ring-Opening Copolymerization of 2,3,4-Tri-O-benzyl (LGTBE) with 2,4-Di-O-benzyl 3-O-Octadecyl 1,6-Anhydro$\beta$-D-glucopyranose (LGDBE3-18) Monomers. A typical procedure for the copolymerization of LGTBE and LGDBE318 monomers with $\mathrm{PF}_{5}$ as catalyst is as follows (number 2 in Table 1). The copolymerization was carried out under a vacuum as low as $10^{-5} \mathrm{mmHg}$ and at $-60^{\circ} \mathrm{C}$. The anhydroglucose monomers (LGTBE $0.475 \mathrm{~g}$ and LGDBE3-18 $0.025 \mathrm{~g}$ ) in dry $\mathrm{CH}_{2} \mathrm{Cl}_{2}(0.5 \mathrm{~mL})$ were stirred in a glass ampoule at room temperature and then $\mathrm{PF}_{5}$ ( $5 \mathrm{~mol} \%$ of the monomers) as a catalyst was transferred into the polymerization ampoule through a glass tube while maintaining the high vacuum condition at liquid $\mathrm{N}_{2}$ temperature. The copolymerization was started at $-60^{\circ} \mathrm{C}$ and continued for $4 \mathrm{~h}$ with stirring. 
TABLE 2: Debenzylation of LGTBE 2,3,4-tri-O-benzyl (LGTBE) with 2,4-di-O-benzyl-3-O-octadecyl 1,6-anhydro- $\alpha$-D-glucopyranose LGDBE3-18 .

\begin{tabular}{|c|c|c|c|c|c|c|c|c|c|}
\hline \multirow{3}{*}{ Number } & \multicolumn{5}{|c|}{ Benzylated polymer } & \multicolumn{4}{|c|}{ Free polymer } \\
\hline & \multicolumn{2}{|c|}{ Proportion } & \multirow{2}{*}{$\begin{array}{l}\text { wt } \\
\mathrm{g}\end{array}$} & \multirow{2}{*}{$\begin{array}{l}\bar{M}_{n}^{\mathrm{b}} \\
\times 10^{3}\end{array}$} & \multirow{2}{*}{$\begin{array}{r}{[\alpha]_{\mathrm{D}}^{25}} \\
\operatorname{deg}\end{array}$} & \multirow{2}{*}{$\begin{array}{c}\text { wt } \\
\mathrm{g}\end{array}$} & \multirow{2}{*}{$\begin{array}{l}\text { Yield } \\
(\%)\end{array}$} & \multirow{2}{*}{$\begin{array}{l}\bar{M}_{n}{ }^{\mathrm{c}} \\
\times 10^{3}\end{array}$} & \multirow{2}{*}{$\begin{array}{c}\text { LGDBE3-18 unit } \\
\text { mol\% }^{\mathrm{e}}\end{array}$} \\
\hline & LGTBE & LGDBE-18 & & & & & & & \\
\hline 1 & 98.7 & 1.3 & 0.315 & 83.5 & +111.2 & 0.115 & 64.9 & $\mathrm{nd}^{\mathrm{d}}$ & 2.8 \\
\hline 2 & 96.8 & 3.2 & 0.4 & 117.6 & +111.6 & 0.116 & 51.7 & nd & 4.7 \\
\hline 3 & 77.8 & 22.2 & 0.367 & 112.5 & +101.2 & 0.177 & 85.9 & nd & 15.7 \\
\hline
\end{tabular}

${ }^{\mathrm{a} C o n d i t i o n: ~} \mathrm{Na} ; 0.4 \mathrm{~g}$, solvent: liq. $\mathrm{NH}_{3} ; 50 \mathrm{~mL}$, time: $90 \mathrm{~min}$, temp.: $-78^{\circ} \mathrm{C}$.

${ }^{\mathrm{b}}$ Calculated by $\mathrm{CHCl}_{3} \mathrm{GPC}$.

${ }^{\mathrm{c} C a l c u l a t e d}$ by aqueous GPC.

${ }^{\mathrm{d}}$ Insoluble in water.

${ }^{\mathrm{e}}$ Calculated from ${ }^{1} \mathrm{H}$ NMR spectrum in DMSO- $\mathrm{d}_{6}$.

Methanol was added at the termination to obtain a precipitate (copolymer). The copolymer obtained was purified by precipitation using hexane- $\mathrm{CHCl}_{3}$ three times and then freezedried from benzene to give a copolymer $(0.46 \mathrm{~g})$ in $91.9 \%$ yield. The molecular weight was $\bar{M}_{n}=83.5 \times 10^{3}$ and specific rotation was $[\alpha]_{\mathrm{D}}^{25}=+111.2^{\circ}$. The proportion of LGDBE318 units in the copolymer was $1.3 \mathrm{~mol} \%$ by calculating the integration value of the ${ }^{1} \mathrm{H} N \mathrm{NMR}$ at $3.25 \mathrm{ppm}$ and $3.35 \mathrm{ppm}$ due to $\mathrm{H} 2$ signals.

2.3. Debenzylation. The copolymer $(0.32 \mathrm{~g}$, number 2 in Table 1) dissolved in $10 \mathrm{~mL}$ of dry dimethoxyethane was added dropwise to $50 \mathrm{~mL}$ of liquid ammonia containing $0.5 \mathrm{~g}$ of sodium at $-78^{\circ} \mathrm{C}$ under nitrogen. After $2 \mathrm{~h}$ of stirring at the same temperature, ammonium chloride was added until the blue-black color had changed to white and then small amount of $\mathrm{MeOH}$ was added to inactivate the sodium that remained. After evaporation of the liquid ammonia at room temperature, water $(50 \mathrm{~mL})$ was poured into the flask. The aqueous solution was washed with $\mathrm{CH}_{2} \mathrm{Cl}_{2}$ to remove organic impurities and then dialyzed for $2 \mathrm{~d}$ with deionized water. The aqueous solution was concentrated to $30 \mathrm{~mL}$ and freeze-dried under vacuum to give debenzylated copolysaccharide $(0.12 \mathrm{~g})$ in $64.9 \%$ yield (number 1 in Table 2). The proportion of 3-Ooctadecyl glucopyranose unit was $2.8 \mathrm{~mol} \%$. This copolysaccharide was difficult to dissolve in water and partially soluble in DMSO.

2.4. Sulfation. The typical procedure for the sulfation is as follows. Piperidine- $N$-sulfonic acid $(1.5 \mathrm{~g})$ was added to the debenzylated copolysaccharide (115 mg) in dry DMSO $(10 \mathrm{~mL})$, and the mixture was stirred for $90 \mathrm{~min}$ at $85^{\circ} \mathrm{C}$ under a nitrogen atmosphere. The mixture was cooled to room temperature, neutralized with $5 \% \mathrm{NaOH}$ aqueous solution, and then dialyzed for $2 \mathrm{~d}$ with deionized water. The dialysate was concentrated to $30 \mathrm{~mL}$ and then freeze-dried to give $145 \mathrm{mg}$ of sulfated glucopyranan with 3-O-octadecyl group in the proportion of $2.8 \mathrm{~mol} \%$ and the $\bar{M}_{n}=5.1 \times 10^{3}$ (number 1 in Table 3). The sulfur concentration was $12.2 \%$ and the degree of sulfation 1.03 .

2.5. Anti-HIV Activity. The anti-HIV activity was assayed by the MTT method using MT-4 cells, which is a human
T4-positive cell line carrying human T-lymphotropic virus type-1, according to the method described in a previous paper [13]. The anti-HIV activity was denoted by the $\mathrm{EC}_{50}$, which is concentration of the sulfated copolysaccharides effective in preventing HIV infection in 50\% of MT- 4 cells. The cytotoxicity was defined as the $\mathrm{CC}_{50}$, which is the concentration sulfated of copolysaccharides that is cytotoxic to $50 \%$ of MT- 4 cells.

\subsection{Interaction between Sulfated Octadecyl Glucopyranan} and Poly-L-lysine. Interaction between sulfated octadecyl glucopyranan and poly-L-lysine was determined by a Biacore X100 SPR instrument at $25^{\circ} \mathrm{C}$ and used dextran sulfate with potent anti-HIV activity $\left(\mathrm{EC}_{50}=0.05 \mu \mathrm{g} / \mathrm{mL}\right)$ as a standard sulfated polysaccharide. Commercially available polyL-lysine (ligand) with the molecular weight of 1000-5000 was used as a model compound of proteins and immobilized on the CM5 sensor chip by an amine coupling method to give 2100 response units (RU), which is an immobilization rate. The sulfated copolysaccharides were dissolved in a HBSEP manufacturer-supplied running buffer and the solution was passed over the surface of the poly-L-lysine immobilized sensor chip at the flow rate of $30 \mu \mathrm{L} / \mathrm{min}$ for $180 \mathrm{sec}$ for association. The running buffer was continuously flowed for a further $600 \mathrm{sec}$ at the same rate for dissociation. The association $\left(k_{a}\right)$ and dissociation rate $\left(k_{d}\right)$ constants were determined by the $1: 1$ binding model using Biacore-supplied software provided by GE Healthcare UK Ltd. The dissociation constant $\left(K_{D}\right)$ was calculated from $k_{a}$ and $k_{d}$.

2.7. Measurement. The ${ }^{1} \mathrm{H}$ NMR $(600 \mathrm{MHz})$ and ${ }^{13} \mathrm{C}$ NMR $(150 \mathrm{MHz})$ spectra were measured on a JEOL ECX-600 spectrometer in $\mathrm{CDCl}_{3}, \mathrm{D}_{2} \mathrm{O}$, or DMSO- $\mathrm{d}_{6}$ solvents. The temperatures used were $25^{\circ} \mathrm{C}$ for the $\mathrm{CDCl}_{3}$ solvent and $40^{\circ} \mathrm{C}$ for $\mathrm{D}_{2} \mathrm{O}$ and DMSO- $\mathrm{d}_{6}$ solvents, respectively. Specific rotation of benzylated copolymers was recorded in $\mathrm{CHCl}_{3}$ at $25^{\circ} \mathrm{C}$ by means of a JASCO DIP-140 digital polarimeter. Infrared spectra were taken on a Perkin Elmer Spectrum One FT-IR spectrometer using a $\mathrm{KBr}$ pellet method. Molecular weight was determined at $40^{\circ} \mathrm{C}$ by an organic phase GPC eluted with $\mathrm{CHCl}_{3}$ equipped with TOSOH TSK-gel columns $(7.6 \mathrm{~mm} \times$ $600 \mathrm{~mm} \times 3)$ of $\mathrm{G} 3000 \mathrm{H}_{\mathrm{XL}}, \mathrm{G} 4000 \mathrm{H}_{\mathrm{XL}}$, and $\mathrm{G} 5000 \mathrm{H}_{\mathrm{XL}}$ for benzylated copolymers using polystyrene (Shodex standard 
TABLE 3: Sulfation and anti-HIV activity of 3-O-octadecyl( $1 \rightarrow 6)-\alpha$-D-glucopyranans ${ }^{\mathrm{a}}$.

\begin{tabular}{|c|c|c|c|c|c|c|c|c|c|c|c|c|c|c|}
\hline \multirow{3}{*}{ Number } & \multirow{2}{*}{\multicolumn{2}{|c|}{$\begin{array}{c}\text { Free 3-O-octadecyl } \\
\text { glucopyranan } \\
\text { Proportion of } \\
\text { 3-O-octadecyl group }\end{array}$}} & \multirow{3}{*}{$\begin{array}{c}\text { PSA } \\
\mathrm{g} \\
\end{array}$} & \multirow{3}{*}{$\begin{array}{c}\text { Temp. } \\
{ }^{\circ} \mathrm{C}\end{array}$} & \multirow{3}{*}{$\begin{array}{c}\text { Time } \\
\mathrm{h}\end{array}$} & \multirow{3}{*}{$\begin{array}{c}\text { Yield } \\
\text { mg }\end{array}$} & \multirow{3}{*}{$\begin{array}{l}\bar{M}_{n} \\
\times 10^{3}\end{array}$} & \multicolumn{6}{|c|}{ Sulfated 3-O-octadecyl glucopyranan } & \multirow{3}{*}{$\begin{array}{l}\mathrm{CC}_{50}{ }^{\mathrm{e}} \\
\mu \mathrm{g} / \mathrm{mL}\end{array}$} \\
\hline & & & & & & & & \multirow[t]{2}{*}{$\mathrm{DP}^{\mathrm{b}}$} & \multicolumn{3}{|c|}{ Elemental analysis } & \multirow[t]{2}{*}{$\mathrm{DS}^{\mathrm{c}}$} & \multirow{2}{*}{$\begin{array}{l}\mathrm{EC}_{50}{ }^{\mathrm{d}} \\
\mu \mathrm{g} / \mathrm{mL}\end{array}$} & \\
\hline & $\mathrm{mg}$ & $\mathrm{mol} \%$ & & & & & & & $\mathrm{C}, \%$ & $\mathrm{H}, \%$ & S, $\%$ & & & \\
\hline 1 & 115 & 2.8 & 1.50 & 85 & 1.5 & 145 & 5.1 & 25.2 & 26.5 & 4.5 & 12.2 & 1.03 & 0.05 & $>162$ \\
\hline 2 & 120 & 2.8 & 1.06 & 85 & 1.5 & 145 & 4.3 & 30.6 & 30.6 & 4.4 & 10.3 & 0.75 & 0.09 & $>163$ \\
\hline 3 & 80 & 2.8 & 0.49 & 85 & 1.5 & 130 & 5.1 & 26.1 & 26.1 & 4.3 & 11.8 & 1.02 & 0.04 & $>200$ \\
\hline 4 & 75 & 4.7 & 0.69 & 85 & 1.5 & 103.5 & 2.5 & 13.5 & 34.9 & 4.9 & 8.6 & 0.55 & 1.25 & $>147$ \\
\hline 5 & 60.5 & 6.7 & 0.58 & 85 & 1 & 95.4 & $-{ }^{f}$ & $-^{\mathrm{f}}$ & 37.6 & 4.7 & 9.5 & 0.57 & 20.34 & $>200$ \\
\hline 6 & 155.4 & 15.7 & 0.92 & 85 & 1 & 262.5 & 5.5 & 29.7 & 47.5 & 6.1 & 8.4 & 0.52 & 6.50 & $>200$ \\
\hline $\begin{array}{l}\text { Dextran } \\
\text { sulfate }\end{array}$ & & & & & & & 8.5 & & & & 18.4 & 2.1 & 0.05 & $>621$ \\
\hline $\begin{array}{l}\text { Curdlan } \\
\text { sulfate }\end{array}$ & & & & & & & 79.0 & & & & 14.1 & 1.4 & 0.18 & $>100$ \\
\hline
\end{tabular}

${ }^{a}$ Sulfation was carried out with piperidine- $N$-sulfonic acid (PSA) in DMSO.

${ }^{\mathrm{b}}$ Degree of polymerization.

${ }^{\mathrm{c}}$ Degree of sulfation.

$\mathrm{d}_{50 \%}$ effective concentration on HIV.

e $50 \%$ cytotoxic concentration on MT4 cell.

${ }^{\mathrm{f}}$ Not determined. It was difficult to dissolve in water.

SM-105) as a reference and by aqueous phase GPC columns $(7.6 \mathrm{~mm} \times 300 \mathrm{~mm} \times 3)$ of $\mathrm{G} 2500 \mathrm{PW}_{\mathrm{XL}}, \mathrm{G}^{2} 000 \mathrm{PW}_{\mathrm{XL}}$, and $\mathrm{G} 4000 \mathrm{PW}_{\mathrm{XL}}$, eluted with $66.7 \mathrm{mmol}$ phosphate buffer $(\mathrm{pH}=$ 6.68) for water-soluble sulfated copolysaccharides using pullulan as a reference. The samples (2 wt\%) were dissolved in $\mathrm{CHCl}_{3}$ or the phosphate buffer and then injected in the GPC apparatus, respectively. The molecular weight was calculated from the calibration curve of standard polystyrene for $\mathrm{CHCl}_{3}$ or pullulan for aqueous solvent. The SPR spectrum was measured on a Biacore X100 instrument at $25^{\circ} \mathrm{C}$ using a CM5 sensor chip. The dynamic light scattering (DLS) and zeta $(\zeta)$ potential were performed at $25^{\circ} \mathrm{C}$ on an Otsuka Electronics ELSZ-1000ZS zeta potential and particle size analyzer in phosphate buffer solution $(\mathrm{pH}=7.4)$ at the concentrations of $1 \mathrm{mg} / \mathrm{mL}$ or $0.5 \mathrm{mg} / \mathrm{mL}$ of sulfated polysaccharides and poly-L-lysine, respectively, and the data were analyzed by the maker provided software.

\section{Results and Discussion}

3.1. Ring-Opening Copolymerization of 2,3,4-Tri-O-benzyl (LGTBE) with 2,4-Di-O-benzyl 3-O-Octadecyl 1,6-Anhydro- $\beta$ D-glucopyranose (LGDBE3-18) Monomers. The polymerization of the 3-O-octadecyl glucose monomer LGDBE3-18 for the purpose of development of polysaccharide-coated liposomes was already reported by Kobayashi et al. [11], indicating that the monomer was polymerized with $\mathrm{PF}_{5}$ as catalyst to give the corresponding $(1 \rightarrow 6)-\alpha$-D-glucopyranoside polymers with high molecular weights.

However, the exact structure of the homopolymers and copolymers has not been reported. Therefore, we examined the copolymerization of LGTBE with LGDBE3-18 and then the structure of the resulting copolymer was investigated by high resolution NMR measurements including 2D NMR.
The monomers were synthesized according to previously reported methods $[5,11]$.

Scheme 1 shows the synthesis route of sulfated copolysaccharides. The two monomers in the various feeds were copolymerized with $\mathrm{PF}_{5}$ as catalyst under pressure below $10^{-5} \mathrm{mmHg}$ at $-60^{\circ} \mathrm{C}$ to give the corresponding copolymers 3 in good yields. After debenzylation with sodium in liquid ammonia to recover hydroxyl groups and then sulfation, sulfated glucopyranans with a long octadecyl group at the $\mathrm{C} 3$ position were obtained. The results of the copolymerization are summarized in Table 1.

The LGDBE3-18 monomer was readily polymerized with $\mathrm{PF}_{5}$ in $4 \mathrm{~h}$ at $-60^{\circ} \mathrm{C}$ to give the corresponding polymer in $91.8 \%$ yield, whose number-average molecular weight $\left(\bar{M}_{n}\right)$ measured by GPC with $\mathrm{CHCl}_{3}$ as an eluent was high, $\bar{M}_{n}=$ $163.1 \times 10^{3}$, as shown in number 8 . When the copolymerization with LGTBE and LGDBE3-18 monomers was carried out with $\mathrm{PF}_{5}$ in the monomer proportions ranging from $3.7 \mathrm{~mol} \%$ to $70 \mathrm{~mol} \%$, the corresponding copolymers were obtained in more than $90 \%$ yields. The molecular weights of the copolymers were also high, giving from $\bar{M}_{n}=65.7 \times 10^{3}$ to $136.5 \times 10^{3}$. Specific rotation values were high and positive for poly(LGTBE) and decreased gradually from $+114.1^{\circ}$ to $+91.4^{\circ}$ (number 7) with an increasing proportion of LGDBE3-18 monomeric units in the feed; poly(LGDBE3-18) gave $+86.9^{\circ}$ $\left(\mathrm{cl}, \mathrm{CHCl}_{3}\right)$. In the ring-opening polymerization of $1,6-$ anhydrosugars, 1,6-scission occurred with a cationic catalyst to form pyranosidic polymers with a $(1 \rightarrow 6)$ linkage. Taking into account the high and positive specific rotations, the copolymers that resulted should have $(1 \rightarrow 6)-\alpha$ stereoregularity.

The proportion of LGDBE3-18 units in the copolymers depended on the monomer feed and ranged from $1.3 \mathrm{~mol} \%$ to $72.9 \mathrm{~mol} \%$, which were calculated from the integration values 

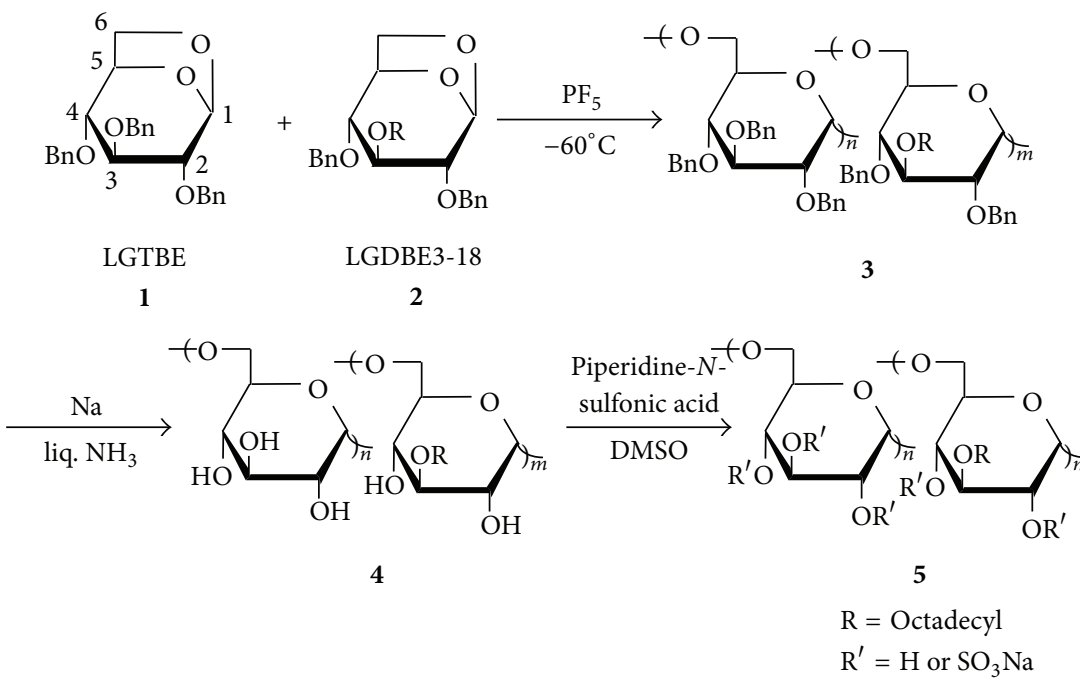

SCHEME 1: Ring-opening copolymerization of 2,3,4-tri-O-benzylated 1,6-anhydroglucose (LGTBE) 1 and 3-O-octadecyl 2,4-di-O-benzyl 1,6anhydroglucose (LGDBE3-18) 2 into sulfated 3-O-octadecyl( $1 \rightarrow 6$ )- $\alpha$-D-glucopyranan $\mathbf{5}$ after debenzylation of $\mathbf{3}$ and subsequent sulfation of 4.

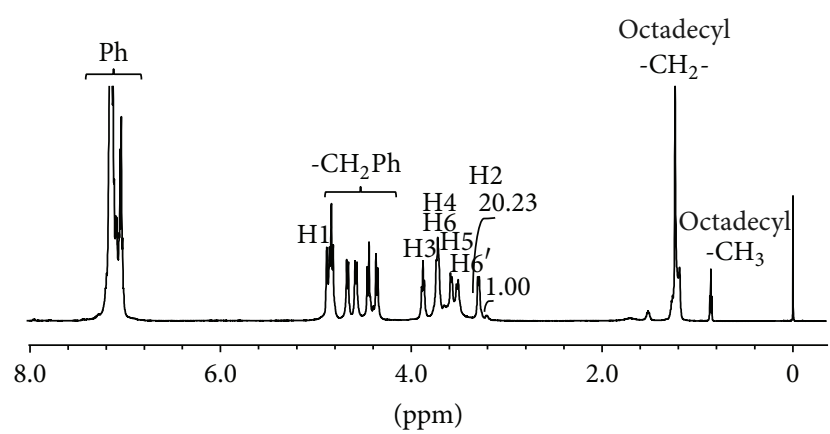

FIGURE 1: $600 \mathrm{MHz}^{1} \mathrm{H}$ NMR spectrum of copoly(LGTBE-LGDBE318) in $\mathrm{CDCl}_{3}$ at room temperature with $\bar{M}_{n}=65.7 \times 10^{3}$ and $[\alpha]_{\mathrm{D}}^{25}=$ $+107.8^{\circ}$. The proportion of LGDBE3-18 units in the copolymer was calculated to be $4.7 \mathrm{~mol} \%$ from the comparison of the integration values of the $\mathrm{H} 2$ signals. LGTBE: 2,3,4-tri- $O$-benzyl 1,6-anhydro- $\beta$ D-glucopyranose, LGDBE3-18: 2,4-di-O-benzyl-3-O-octadecyl 1,6anhydro- $\beta$-D-glucopyranose.

in the ${ }^{1} \mathrm{H}$ NMR spectra at $3.32 \mathrm{ppm}$ and $3.22 \mathrm{ppm}$ due to the $\mathrm{H} 2$ proton in LGTBE and LGDBE3-18 residues, respectively.

Figure 1 shows the ${ }^{1} \mathrm{H}$ NMR spectrum of the copolymer of LGTBE and LGDBE3-18 units in the proportion of $90: 10 \mathrm{~mol} \%$ in feed. From the integration value at $3.25 \mathrm{ppm}$ to $3.35 \mathrm{ppm}$, the proportion of LGDBE3-18 units in the copolymer was calculated to be $4.7 \mathrm{~mol} \%$ (number 4 in Table 1). All ${ }^{1} \mathrm{H}$ signals were assigned by the $\mathrm{H}-\mathrm{H}$ COSY spectrum. Figure 2 represents the ${ }^{13} \mathrm{C}$ NMR spectra of the copolymers in $\mathrm{CDCl}_{3}$ at $25^{\circ} \mathrm{C}$. Figures $2(\mathrm{a})$ and $2(\mathrm{f})$ are spectra of homopolymers of LGTBE and LGDBE3-18 monomers, respectively. The $\mathrm{C} 1$ carbon signals appeared at $97.9 \mathrm{ppm}$ in both Figures 2(a) and 2(f) spectra as singlet signals, revealing that the polymers have high stereoregularity. All signals were assigned by the combination of $\mathrm{H}-\mathrm{H}$ COSY and
HMQC 2D NMR measurements. The terminal methyl signal of octadecyl group appeared at $13 \mathrm{ppm}$ and methylene signals also appeared between 22 and $32 \mathrm{ppm}$. A methylene signal next to oxygen at the C3 position of LGDBE3-18 residue was found to be shifted to a lower magnetic field at $74 \mathrm{ppm}$. For the copolymers having the 3-O-octadecyl group shown in Figures 2(b) to 2(e), the carbon signals due to glucopyranose units appeared in almost the same positions as those of homopolymers. With the increase of the proportion of LGDBE318 units, the intensity of octadecyl carbon signals and the protective benzyl signal at the C3 position of the LGTBE unit gradually increased and decreased, respectively. The results of the NMR and specific rotations in Table 1 indicate that the homo and copolymers had high stereoregularity and were composed of $(1 \rightarrow 6)$ - $\alpha$ linked glucopyranoside units.

3.2. Deprotection of Benzyl Groups in Copolymers. Removal of benzyl groups from the benzylated copolymers with 3$O$-octadecyl groups in proportions below $22.2 \mathrm{~mol} \%$ was carried out with sodium in liquid ammonia to give $\mathrm{OH}$-free glucopyranans with a 3-O-octadecyl group. The results are shown in Table 2 . The $\mathrm{OH}$-free glucopyranans were insoluble in water and partially soluble in DMSO, so it was impossible to measure their molecular weights and specific rotations. However, the molecular weights of the OH-free glucopyranans were estimated to be relatively high. After debenzylation, the characteristic IR absorptions of large hydroxyl and octadecyl groups appeared at $3413 \mathrm{~cm}^{-1}$ and $2925 \mathrm{~cm}^{-1}$, respectively, indicating that the substituted octadecyl group at the $\mathrm{C} 3$ position still remained. However, the proportion decreased somewhat before debenzylation as measured by NMR, probably because the debenzylation was performed by strong alkaline conditions. Figure 3 exhibits the ${ }^{13} \mathrm{C} N \mathrm{NMR}$ spectra of the OH-free glucopyranans with 3-O-octadecyl group in the proportion of 2.8 to $15.7 \mathrm{~mol} \%$ in $\mathrm{DMSO}-\mathrm{d}_{6}$ 


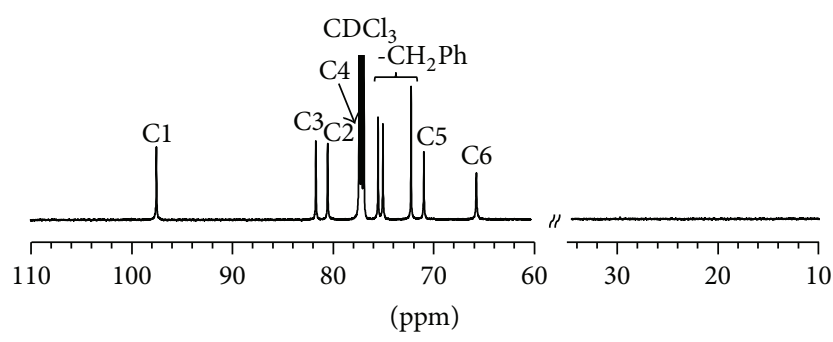

(a)

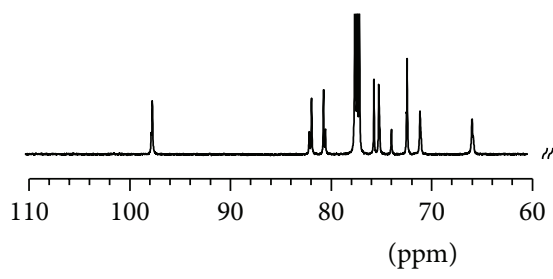

(c)

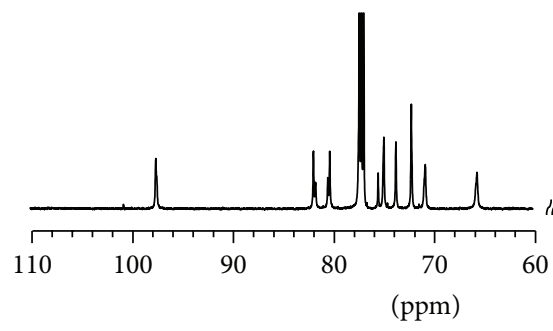

(e)

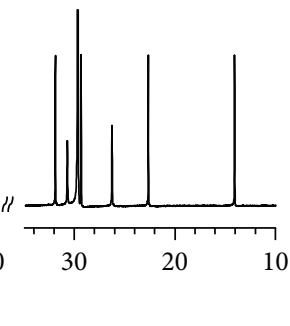

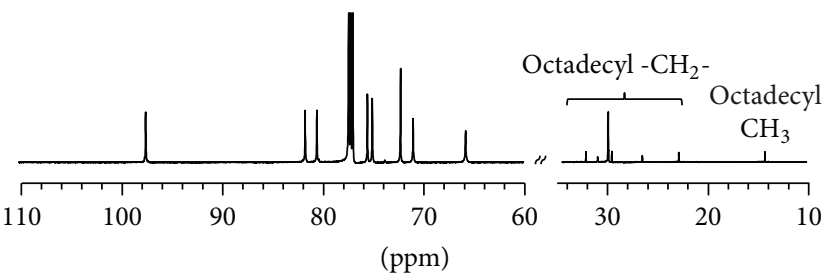

(b)

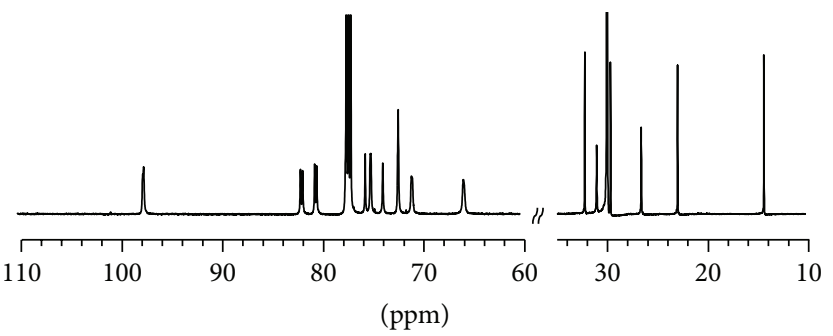

(d)

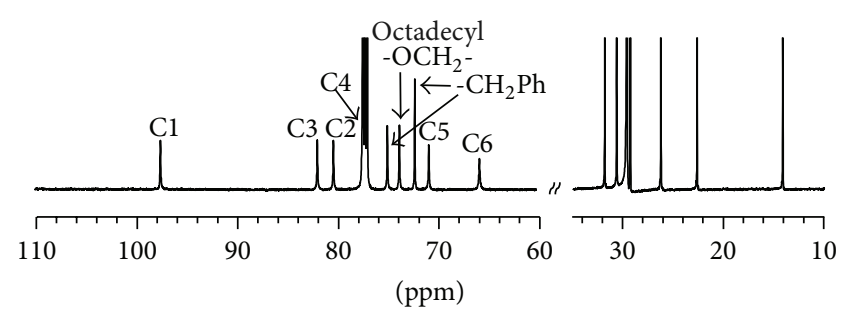

(f)

Figure 2: $150 \mathrm{MHz}{ }^{13} \mathrm{C}$ NMR spectra of copoly(LGTBE-LGDBE3-18)s in $\mathrm{CDCl}_{3}$ at room temperature. (a) Poly(LGDBE), (b)-(e) copoly(LGTBE-LGDBE3-18)s with the proportion of LGDBE3-18 units of 1.3, 22.2, 46.9, and 72.9 mol\%, respectively, and (f) poly(LGDBE318), in which polymers are corresponding in Table 1 . The signals were assigned by a combination of H-H COSY and HMQC measurements.

at $40^{\circ} \mathrm{C}$. The methylene signals due to the protective benzyl group between $70 \mathrm{ppm}$ and $80 \mathrm{ppm}$ disappeared, suggesting that debenzylation proceeded to recover hydroxyl groups without elimination of the octadecyl group, because the 3$O$-octadecyl signals appeared between $17 \mathrm{ppm}$ and $33 \mathrm{ppm}$. The $\mathrm{C}^{\prime}$ signal due to the 3-O-octadecyl glucopyranoside residue appeared clearly at $82.9 \mathrm{ppm}$ and increased gradually in intensity with the increase in the proportion of the 3-Ooctadecyl group in the glucopyranans. The proportion of the octadecyl group was calculated from the integration values at $3.72 \mathrm{ppm}$ and $0.81 \mathrm{ppm}$ due to the $\mathrm{H} 2$ signal of the glucose residue and the terminal $\mathrm{CH}_{3}$ signal of 3-O-octadecyl group, respectively, in the ${ }^{1} \mathrm{H}$ NMR spectrum.

\subsection{Sulfation of 3-O-Octadecyl Glucopyranans and Their Bio-} logical Activity. We reported the anti-HIV activity of sulfated $(1 \rightarrow 6)-\alpha$-D-glucopyranan prepared by the ring-opening polymerization of LGTBE monomer and then debenzylation [8]. Sulfation of glucopyranans with the 3-O-octadecyl group in proportions below $15.7 \mathrm{~mol} \%$ was performed by piperidine- $N$-sulfonic acid in DMSO at $85^{\circ} \mathrm{C}$ to give sulfated $(1 \rightarrow 6)$ - $\alpha$-D-glucopyranans with a 3 -O-octadecyl group. The results are listed in Table 3.
After sulfation, the sulfated glucopyranans were soluble in water, and their molecular weights were $2.5 \times 10^{3}-5.5 \times 10^{3}$ except number 5 in Table 3 . The molecular weight of sulfated 3-O-octadecyl glucopyranans decreased by sulfation because the procedure of sulfation was performed under acidic conditions. The solubility of number 5 sulfated glucopyranan in water was low probably because the degree of sulfation was low and the molecular weight should be relatively high.

Figure 4 shows the ${ }^{13} \mathrm{C}$ NMR spectrum of the sulfated glucopyranan with 3-O-octadecyl group in the proportion of $2.8 \mathrm{~mol} \%$ and the molecular weight of $\bar{M}_{n}=5.1 \times 10^{3}$ (number 1 in Table 3). After sulfation, signals broadened and shifted to a lower or higher magnetic field, suggesting that the sulfate group was introduced into the hydroxyl groups of the glucopyranoside units. The C1, C3, and C5 signals due to glucopyranoside residue appeared at $97 \mathrm{ppm}, 79 \mathrm{ppm}$, and $66 \mathrm{ppm}$, respectively. The $\mathrm{C} 2, \mathrm{C} 4$, and $\mathrm{C} 5$ signals appeared between $69 \mathrm{ppm}$ and $77 \mathrm{ppm}$. The terminal methyl signal due to octadecyl group appeared at $14.5 \mathrm{ppm}$ and other signals were absorbed between 22 and $32 \mathrm{ppm}$. The methylene signal next to oxygen $\left(-\mathrm{OCH}_{2}-\right)$ at the $\mathrm{C} 3$ position should appear around $70 \mathrm{ppm}$, a signal overlapped by other signals. The degree of sulfation was calculated to be 1.03 from the ratio of 


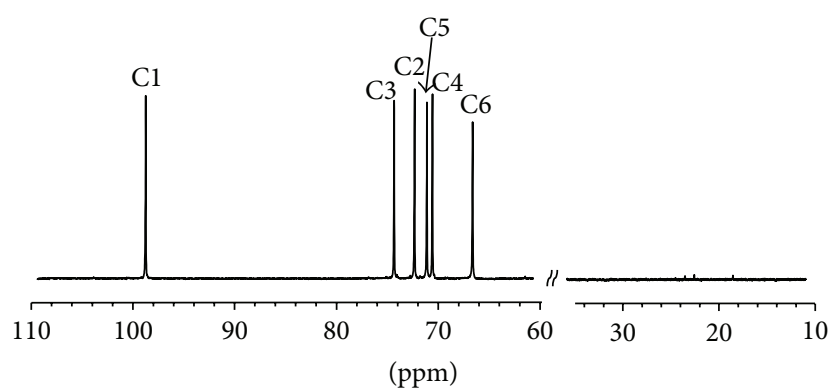

(a)

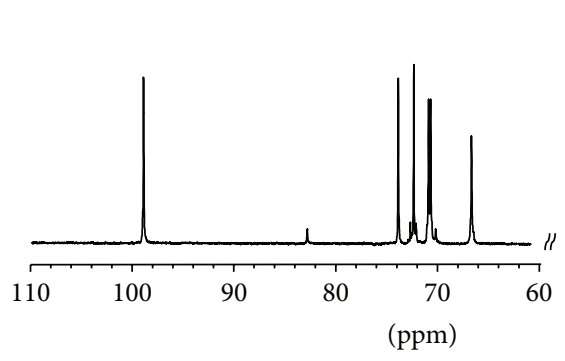

(c)

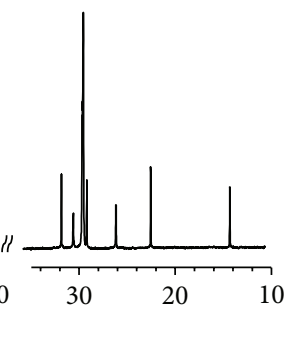

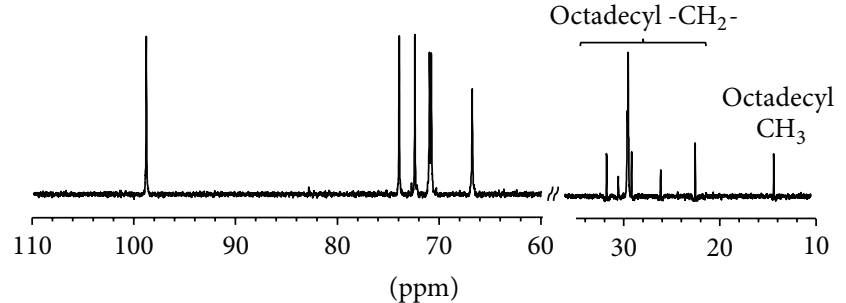

(b)
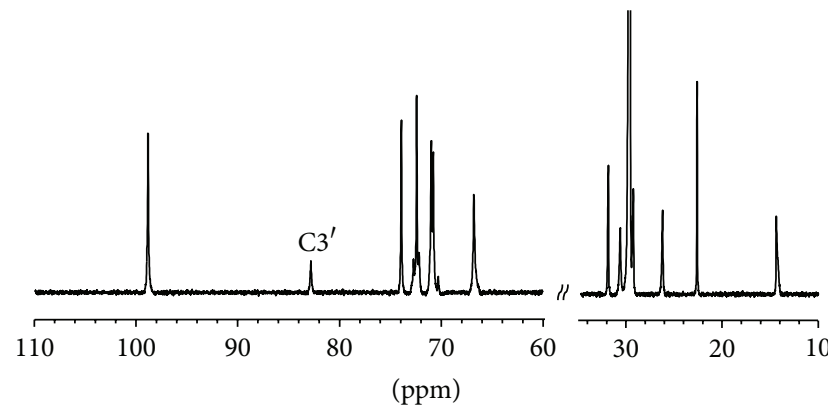

(d)

Figure 3: $150 \mathrm{MHz}{ }^{13} \mathrm{C}$ NMR spectra of $(\mathrm{a})(1 \rightarrow 6)$ - $\alpha$-D-glucopyranan in $\mathrm{D}_{2} \mathrm{O}$ and (b)-(d) $(1 \rightarrow 6)$ - $\alpha$-D-glucopyranans with 3-O-octadecyl groups in the proportion of $2.8,4.7$, and $15.7 \mathrm{~mol} \%$ in $\mathrm{DMSO}-\mathrm{d}_{6}$ at $40^{\circ} \mathrm{C}$. The $\mathrm{C}^{\prime}{ }^{\prime}$ signal due to 3 -O-octadecyl glucopyranoside residue appeared at $82.8 \mathrm{ppm}$ and the octadecyl $-\mathrm{OCH}_{2}$ - signal should overlap around $70-73 \mathrm{ppm}$.

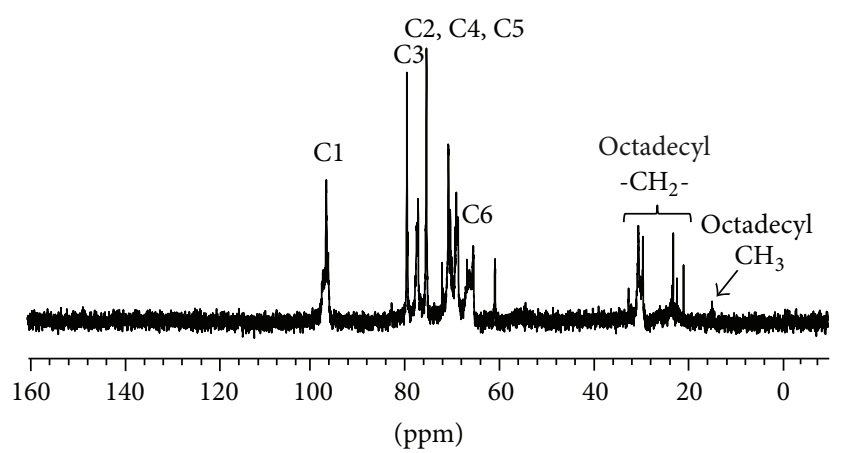

Figure 4: $150 \mathrm{MHz}{ }^{13} \mathrm{C}$ NMR spectrum of sulfated $(1 \rightarrow 6)-\alpha$ D-glucopyranan with 3-O-octadecyl groups in the proportion of $2.8 \mathrm{~mol} \%$ in $\mathrm{D}_{2} \mathrm{O}$ at $40^{\circ} \mathrm{C}$. The degree of sulfation was 1.03 and $\bar{M}_{n}=5.1 \times 10^{3}$.

carbon to sulfur in the elemental analysis as shown in Table 3. In the FT-IR spectra, the large absorption of hydroxyl groups still remained after sulfation because the sulfate groups were introduced into the hydroxyl groups in the proportion below $1 / 3$. The large absorption due to sulfate group appeared at $1261 \mathrm{~cm}^{-1}$.

The results of anti-HIV activity of sulfated 3-O-octadecyl glucopyranans are also listed in Table 3 , indicating that the dextran and curdlan sulfates with a high degree of sulfation used as a standard had potent anti-HIV activity. A sulfated 3-O-octadecyl glucopyranan with a lower degree of sulfation (number 5) and low solubility in water had lower anti-HIV activity. However, a water-soluble sulfated 3-O-octadecyl glucopyranan with $\bar{M}_{n}=5.1 \times 10^{3}$ had high anti-HIV activity at concentrations as low as $0.05 \mu \mathrm{g} / \mathrm{mL}$ (number 1), even though the sulfated glucopyranan had a low molecular weight. Other sulfated 3-O-octadecyl glucopyranans had high anti-HIV activity. Previously, we reported the effect of the relationship between the molecular weight and the long alkyl group on the anti-HIV activity of sulfated ribofuranans. A sulfated ribofuranan with $\bar{M}_{n}=6 \times 10^{3}$ showed low anti-HIV activity with an $\mathrm{EC}_{50}=68.6 \mu \mathrm{g} / \mathrm{mL}$. After introduction of an octadecyl group, the anti-HIV activity increased to $\mathrm{EC}_{50}=$ $0.6 \mu \mathrm{g} / \mathrm{mL}$ and $2.5 \mu \mathrm{g} / \mathrm{mL}$ for sulfated octadecyl ribofuranans with $\bar{M}_{n}=6 \times 10^{3}$ and $\bar{M}_{n}=3 \times 10^{3}$, respectively. Therefore, we considered that sulfated 3-O-octadecyl glucopyranans with lower molecular weights had high anti-HIV activity. A sulfated 3-O-octadecyl glucopyranan with the low molecular weight of $\bar{M}_{n}=2.5 \times 10^{3}$ had, in fact, high anti-HIV activity at concentrations as low as $1.25 \mu \mathrm{g} / \mathrm{mL}$ (number 4 in Table 3). The introduction of the long alkyl group increased anti-HIV activity of sulfated polysaccharides with lower molecular weights [14]. The mechanism is still unclear. We have continuously investigated the effect of long alkyl chain on anti-HIV activity.

3.4. Interaction of Sulfated 3-O-Octadecyl Glucopyranans with Poly-L-lysine. The interaction between sulfated 3-Ooctadecyl glucopyranan having $\bar{M}_{n}=5.1 \times 10^{3}$ and DS = 1.03 and poly-L-lysine as a model protein was quantitatively analyzed by using SPR. Figure 5 shows the binding curves of 
TABLE 4: Apparent kinetic results ${ }^{\mathrm{a}}$ and DLS measurements ${ }^{\mathrm{b}}$ of 3-O-octadecyl $(1 \rightarrow 6)$ - $\alpha$-D-glucopyranans in the presence or absence of polyL-lysine.

\begin{tabular}{|c|c|c|c|c|c|c|c|c|c|c|}
\hline \multirow{4}{*}{ Number } & \multirow{4}{*}{$\begin{array}{l}\text { Proportion of } \\
\text { 3-O-octadecyl } \\
\text { group } \\
\text { mol\% }\end{array}$} & \multirow{4}{*}{$\begin{array}{l}\bar{M}_{n} \\
\times 10^{3}\end{array}$} & \multirow{4}{*}{$\mathrm{DS}^{\mathrm{d}}$} & \multirow{2}{*}{\multicolumn{3}{|c|}{ Kinetic result }} & \multicolumn{4}{|c|}{ Poly-L-lysine $e^{c}$} \\
\hline & & & & & & & \multicolumn{2}{|c|}{ Present } & \multicolumn{2}{|c|}{ Absent } \\
\hline & & & & $k_{a}$ & $k_{d}$ & $K_{D}$ & Particle size & $\zeta$ & Particle size & $\zeta$ \\
\hline & & & & $1 / \mathrm{Ms}$ & $1 / \mathrm{s}$ & $\mathrm{M}$ & $\mathrm{nm}$ & $\mathrm{mV}$ & $\mathrm{nm}$ & $\mathrm{mV}$ \\
\hline 1 & 2.8 & 5.1 & 1.03 & $8.1 \times 10^{4}$ & $3.7 \times 10^{-4}$ & $4.6 \times 10^{-9}$ & $181.9 \pm 50.6$ & -24.44 & $69.6 \pm 19.8$ & -30.61 \\
\hline 2 & 2.8 & 4.3 & 0.75 & $4.9 \times 10^{4}$ & $3.3 \times 10^{-4}$ & $6.8 \times 10^{-9}$ & $147.6 \pm 45.8$ & -18.10 & $81.1 \pm 0.0$ & -18.43 \\
\hline 3 & 2.8 & 5.1 & 1.02 & $8.0 \times 10^{4}$ & $3.1 \times 10^{-4}$ & $3.9 \times 10^{-9}$ & $129.4 \pm 31.9$ & -15.91 & $63.1 \pm 12.3$ & -18.27 \\
\hline 4 & 4.7 & 2.5 & 0.55 & $6.8 \times 10^{4}$ & $1.0 \times 10^{-3}$ & $1.6 \times 10^{-8}$ & $91.3 \pm 35.1$ & -16.15 & $47.4 \pm 6.6$ & -18.0 \\
\hline $5^{\mathrm{e}}$ & 6.7 & - & 0.57 & $6.6 \times 10^{4}$ & $1.1 \times 10^{-3}$ & $1.5 \times 10^{-8}$ & $56.9 \pm 42.4$ & -5.14 & $46.6 \pm 5.9$ & -9.95 \\
\hline 6 & 15.7 & 5.5 & 0.52 & $4.3 \times 10^{4}$ & $4.2 \times 10^{-3}$ & $1.0 \times 10^{-8}$ & $64.2 \pm 20.5$ & -14.23 & $63.0 \pm 22.8$ & -20.09 \\
\hline $\begin{array}{l}\text { Dextran } \\
\text { sulfate }^{\mathrm{f}}\end{array}$ & & 8.5 & 2.1 & $29.0 \times 10^{4}$ & $1.9 \times 10^{-4}$ & $0.7 \times 10^{-9}$ & $161.2 \pm 42.9$ & -11.87 & $50.3 \pm 9.5$ & -4.67 \\
\hline
\end{tabular}

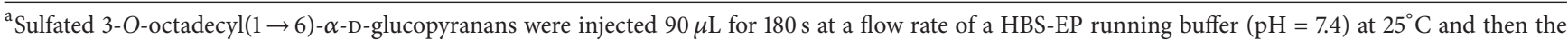
running buffer was further flowed for $600 \mathrm{~s}$. Concentrations of 3-O-octadecyl $(1 \rightarrow 6)$ - $\alpha$-D-glucopyranans were $500,250,125,62.5$, and $31.3 \mu \mathrm{g} / \mathrm{mL}$, respectively. CM5 sensor chip immobilized poly-L-lysine was used.

${ }^{\mathrm{b}}$ The particle size $(\mathrm{nm})$ and zeta potential $(\mathrm{mV})$ of the sulfated 3-O-octadecyl $(1 \rightarrow 6)-\alpha$-D-glucopyranans in the presence or absence of poly-L-lysine were determined at $25^{\circ} \mathrm{C}$ by a dynamic light scattering measurement in phosphate buffer solution $(\mathrm{pH}=7.4)$ at a concentration of $1 \mathrm{mg} / \mathrm{mL} \mathrm{or} 0.5 \mathrm{mg} / \mathrm{mL}$. Before measuring, all samples were subjected to ultrasonication for $5 \mathrm{~min}$.

${ }^{c}$ Commercially available poly-L-lysine $(1 \mathrm{mg} / \mathrm{mL}$ or $0.5 \mathrm{mg} / \mathrm{mL})$ with the molecular weight of $1000-5000$ was used. The particle size and zeta potential were $40.7 \pm 6.9 \mathrm{~nm}$ and $+0.41 \mathrm{mV}$, respectively.

${ }^{\mathrm{d}}$ Degree of sulfation was calculated from the results of the elemental analysis.

${ }^{\mathrm{e}}$ Soluble part in phosphate buffer $(\mathrm{pH}=7.4)$ was measured.

f Standard dextran sulfate with $\bar{M}_{n}=8.5 \times 10^{3}$ was used.

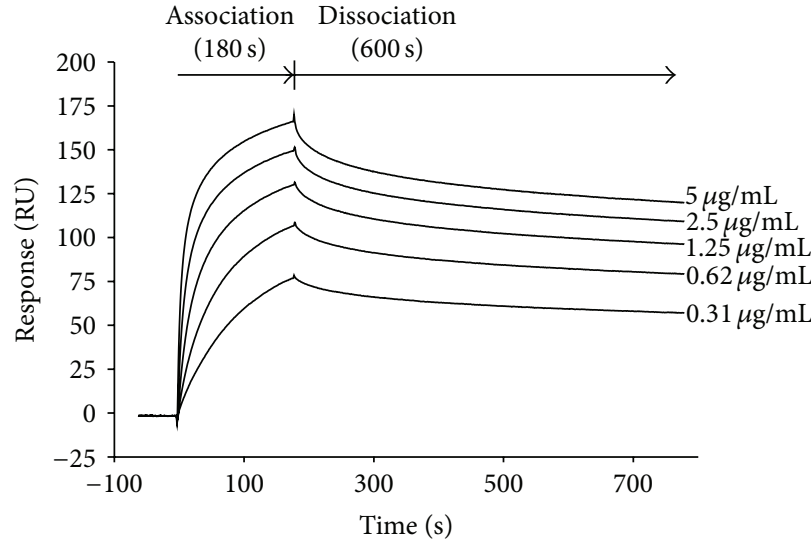

(a)

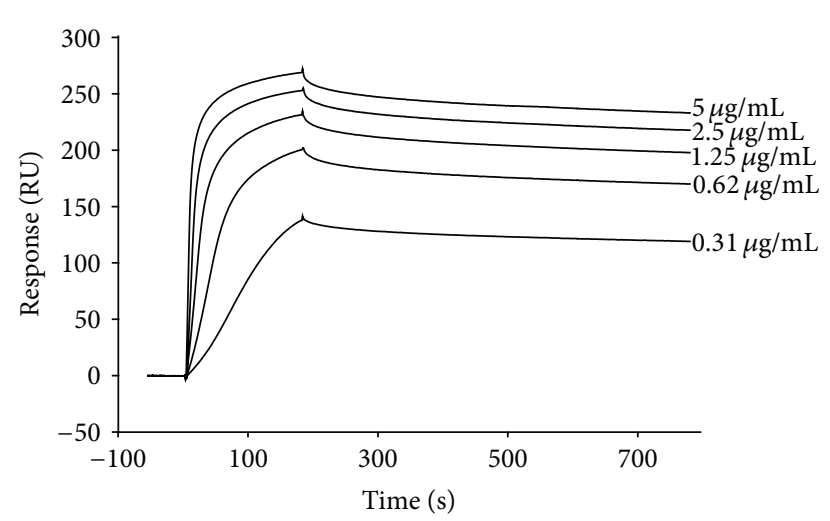

(b)

FIGURE 5: SPR binding affinity of (a) sulfated $(1 \rightarrow 6)$ - $\alpha$-D-glucopyranan with 3-O-octadecyl groups in the proportion of 2.8 mol\% and with $\bar{M}_{n}=5.1 \times 10^{3}$ and (b) dextran sulfate with $\bar{M}_{n}=8.5 \times 10^{3}$ to poly-L-lysine, respectively. The apparent kinetic constants were $k_{a}=8.1 \times$ $10^{4} 1 / \mathrm{Ms}, k_{d}=3.7 \times 10^{-4} \mathrm{l} / \mathrm{s}$, and $K_{D}=4.6 \times 10^{-9} \mathrm{M}$ for sulfated 3-O-octadecyl $(1 \rightarrow 6)$ - $\alpha$-D-glucopyranan $(\mathrm{a})$ and $k_{a}=29.0 \times 10^{4} 1 / \mathrm{Ms}$, $k_{d}=1.89 \times 10^{-4} 1 / \mathrm{s}$, and $K_{D}=0.65 \times 10^{-9} \mathrm{M}$ for standard dextran sulfate.

the sulfated 3-O-octadecyl glucopyranan in the concentration range of $0.31-5.0 \mu \mathrm{g} / \mathrm{mL}$ on a commercially available polyL-lysine with the molecular weight of $M_{w}=1000-5000$, which was immobilized on the CM5 sensor chip at the concentration of $2100 \mathrm{RU}$. The interaction was compared to that of dextran sulfate, a standard sulfated polysaccharide with potent anti-HIV activity as shown in Table 3 . Table 4 summarizes the apparent kinetic results of the sulfated 3-O-octadecyl glucopyranans with poly-L-lysine calculated from the 1:1 binding model. In numbers $1-3$, the sulfated 3-O-octadecyl glucopyranans with higher DS had higher association rate constants, $k_{a}=8.0 \times 10^{4} \mathrm{1} / \mathrm{Ms}-9.4 \times 10^{4} \mathrm{1} / \mathrm{Ms}$, lower dissociation rate constants, $k_{d}=3.7 \times 10^{-4} 1 / \mathrm{s}-3.1 \times 10^{-4} 1 / \mathrm{s}$, and lower dissociation constants $K_{D}=6.8 \times 10^{-9} \mathrm{M}-3.9 \times$ $10^{-9} \mathrm{M}$, indicating that the binding constants were almost the same orders of those of the standard dextran sulfate, $k_{a}=$ $29.0 \times 10^{4} 1 / \mathrm{Ms}, k_{d}=1.89 \times 10^{-4} 1 / \mathrm{s}$, and $K_{D}=0.65 \times 10^{-9} \mathrm{M}$, respectively. In numbers $4-6,3-O$-octadecyl glucopyranans with lower DS gave the lower apparent $k_{a}$ and higher $k_{d}$, suggesting that the interaction was attributed to the DS. 
Table 4 also represents the particle size and zeta $(\zeta)$ potential of the sulfated 3-O-octadecyl glucopyranans in the absence and the presence of poly-L-lysine in phosphate buffer solution $(\mathrm{pH}=7.4)$. The particle size of the sulfated 3-O-octadecyl glucopyranans with higher DS remarkably increased with addition of poly-L-lysine compared to those with lower DS, indicating that the DS of sulfated 3-Ooctadecyl glucopyranans contributed to the interaction with poly-L-lysine. The absolute value of the $\zeta$ potential of the sulfated 3-O-octadecyl glucopyranans decreased after addition of poly-L-lysine probably because the sulfated 3-O-octadecyl glucopyranans with poly-L-lysine were in an aggregate state. These results of SPR and DLS suggest that the interaction was attributable to the electrostatic interaction between the negatively charged sulfate groups of the sulfated 3-Ooctadecyl glucopyranan and the positively charged amino groups of poly-L-lysine. In this interaction, the long octadecyl group was independent and the participation of the long alkyl chain in anti-HIV activity was still unclear. However, we previously reported that introduction of a long alkyl chain into sulfated ribofuranans with low molecular weights and oligosaccharides, respectively, increased anti-HIV activity as high as that of standard curdlan sulfate and dextran sulfate with higher molecular weights and high anti-HIV activity. Therefore, we have continuously investigated the synergistic role of the long alkyl chain in anti-HIV activity. By using the hydrophobicity of the octadecyl group of the sulfated 3-Ooctadecyl glucopyranan, we will develop a new biomaterial that has entrapment functionality for viruses such as HIV, influenza, and Dengue depending on the hydrophilic sulfated polysaccharides immobilized on the hydrophobic surface.

\section{Conclusions}

In conclusion, sulfated 3-O-octadecyl glucopyranans were prepared by the ring-opening copolymerization of benzylated 1,6-anhydroglucose and 3-O-octadecyl 1,6-anhydroglucose monomers and subsequent debenzylation to recover hydroxyl groups and sulfation. The structure of the 3-Ooctadecyl glucopyranans was determined by using high resolution NMR measurements. It was preliminarily found that sulfated 3-O-octadecyl glucopyranans with low molecular weights had high anti-HIV activity and fast association and slow dissociation constants on poly-L-lysine as a model compound of proteins by using SPR measurement. The octadecyl group could be independent of the binding of the sulfated glucopyranans to poly-L-lysine; however, it could produce hydrophobicity around HIV to enhance the activity. We continue to investigate the anti-HIV mechanism of sulfated polysaccharides with long alkyl groups and development of a new biomaterial with a virus-capturing function by utilizing the amphiphilic interaction of hydrophilic sulfated polysaccharides and hydrophobic long alkyl groups.

\section{Conflict of Interests}

The authors declare that there is no conflict of interests regarding the publication of this paper.

\section{Acknowledgment}

This research was partly supported by a Grant-in-Aid for Scientific Research (C) from Japan Society for the Promotion of Science 2012-2014 (no. 24550129).

\section{References}

[1] C. Schuerch, "The chemical synthesis and properties of polysaccharides of biomediated interest," Advances in Polymer Science, vol. 10, pp. 173-194, 1972.

[2] C. Schuerch, "Synthesis and polymerization of anhydro sugars," Advances in Carbohydrate Chemistry and Biochemistry, vol. 39, pp. 157-212, 1981.

[3] T. Uryu, "Artificial polysaccharides and their biological activities," Progress in Polymer Science, vol. 18, no. 4, pp. 717-761, 1993.

[4] M. Okada, "Ring-opening polymerization of bicyclic and spiro compounds. Reactivities and polymerization mechanisms," Advances in Polymer Science, vol. 102, pp. 1-46, 1992.

[5] E. R. Ruckel and C. Schuerch, "Preparation of high polymers from 1, 6-anhydro-2, 3, 4-tri-O-substituted $\beta$ D-glucopyranose," Journal of Organic Chemistry, vol. 31, no. 7, pp. 2233-2239, 1966.

[6] T. Yoshida, "Synthesis of polysaccharides having specific biological activities," Progress in Polymer Science, vol. 26, no. 3, pp. 379-441, 2001.

[7] T. Harada and A. Harada, "Curdlan and succinoglycan," in Polysaccharides in Medical Application, S. Dumitriu, Ed., pp. 2158, Marcel Dekker, New York, NY, USA, 1996.

[8] T. Muschin, S. Han, T. Kanamoto, H. Nakashima, and T. Yoshida, "Synthesis and specific influenza A virus-adsorptive functionality of alkyl curdlan sulfate-coated membrane filter," Journal of Polymer Science, Part A: Polymer Chemistry, vol. 49, no. 15, pp. 3241-3247, 2011.

[9] K. Ichiyama, S. B. Gopala Reddy, L. F. Zhang et al., "Sulfated polysaccharide, curdlan sulfate, efficiently prevents entry/fusion and restricts antibody-dependent enhancement of dengue virus infection in vitro: a possible candidate for clinical application," PLoS Neglected Tropical Diseases, vol. 7, no. 4, Article ID e2188, 2013.

[10] T. Muschin, S. Han, H. Ishimura, and T. Yoshida, "Sulfated polysaccharides as specific biologically active materials," Trends in Glycoscience and Glycotechnology, vol. 23, no. 134, pp. 292305, 2011.

[11] K. Kobayashi, H. Sumitomo, and H. Ichikawa, "Regioselectively modified stereoregular polysaccharides. 8. Synthesis and functions of partially 3-O-octadecylated $(1 \rightarrow 6)-\alpha$-Dglucopyranans," Macromolecules, vol. 19, no. 3, pp. 529-535, 1986.

[12] K. Nagasawa and H. Yoshidome, "Solvent catalytic degradation of sulfamic acid and its $N$-substituted derivatives," Chemical \& Pharmaceutical Bulletin, vol. 17, no. 7, pp. 1316-1323, 1969.

[13] R. Pauwels, J. Balzarini, M. Baba et al., "Rapid and automated tetrazolium-based colorimetric assay for the detection of antiHIV compounds," Journal of Virological Methods, vol. 20, no. 4, pp. 309-321, 1988.

[14] K. Katsuraya, K.-J. Jeon, H. Nakashima, and T. Uryu, "NMR studies on structure and action mechanism of sulfated dodecyl laminaripentaoside with high anti-human immunodeficiency virus activity," Polymer Journal, vol. 31, no. 11, pp. 924-928, 1999. 

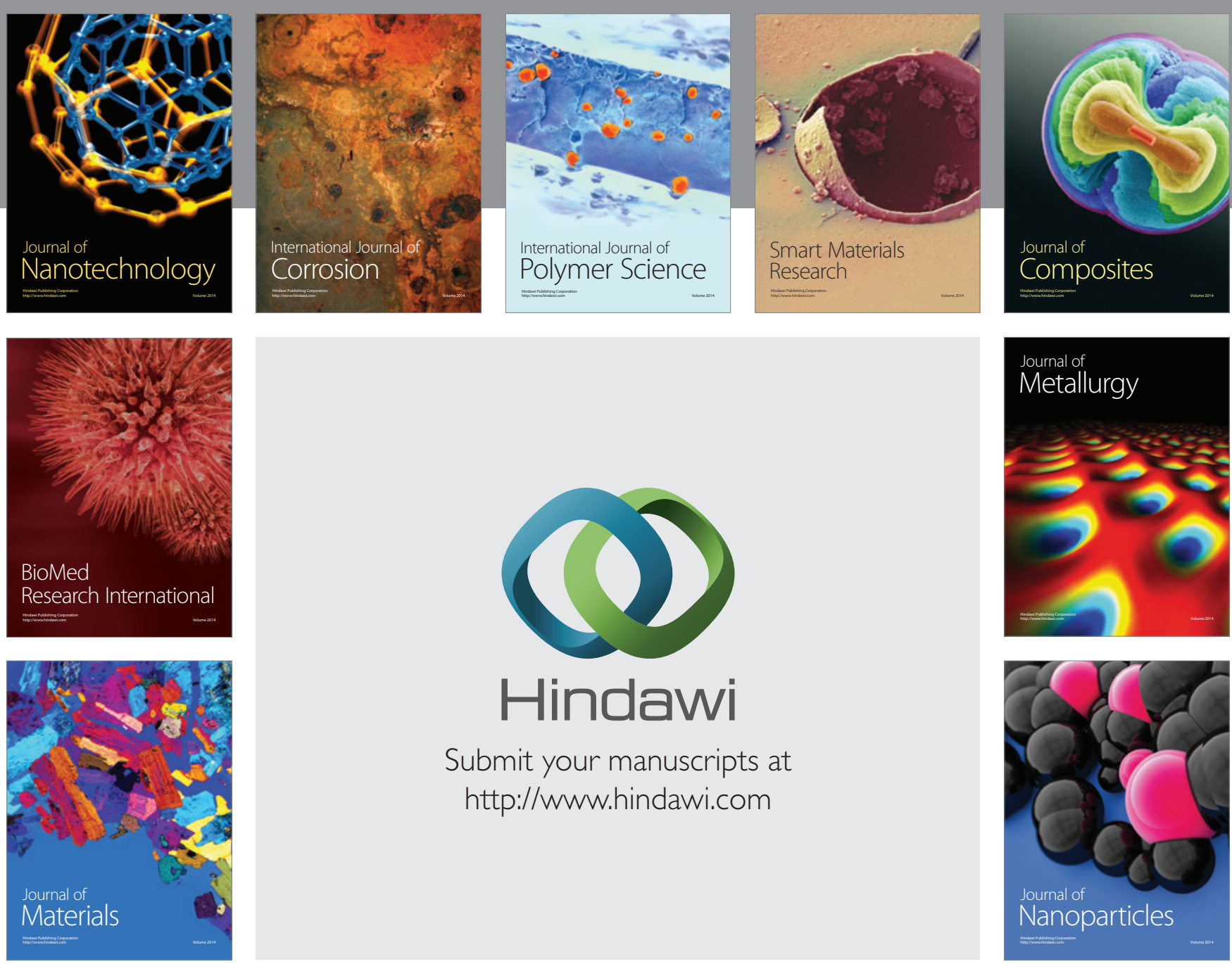

Submit your manuscripts at http://www.hindawi.com
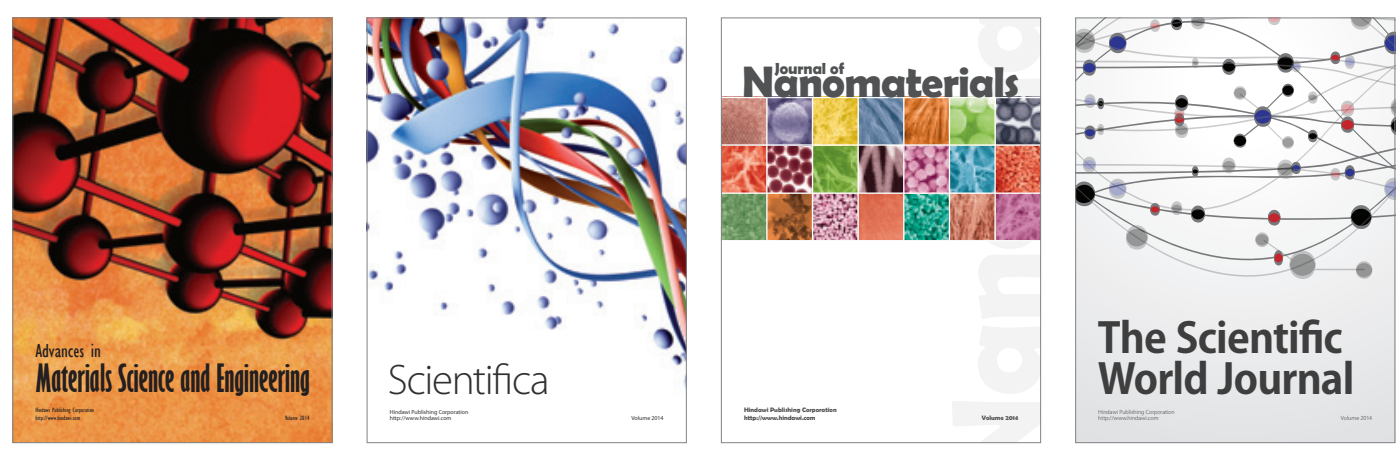

\section{The Scientific World Journal}
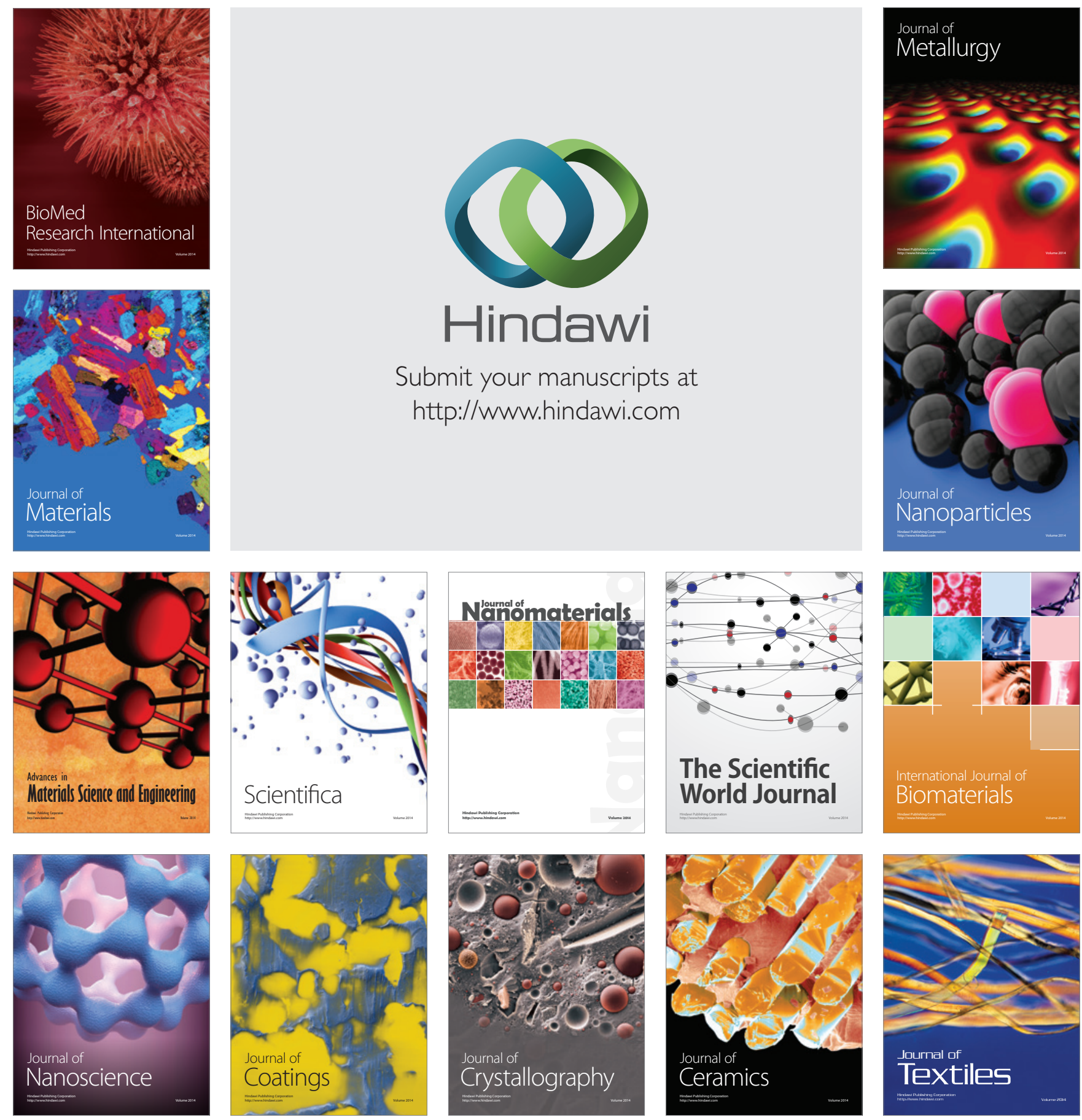